\title{
The relationship between nomophobia level and worry severity in future healthcare professional candidates
}

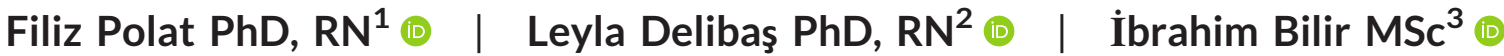

${ }^{1}$ Department of Midwife, Osmaniye Korkut Ata University Faculty of Health Sciences, Osmaniye, Turkey

${ }^{2}$ Department of Dialysis, Hasan Kalyoncu University Vocational School, Gaziantep, Turkey

${ }^{3}$ Department of First and Emergency Aid, Hasan Kalyoncu University Vocational School, Gaziantep, Turkey

Correspondence

Filiz Polat, PhD, RN, Department of Midwife, Osmaniye Korkut Ata University Faculty of Health Sciences, Osmaniye 80010, Turkey. Email: filizmermer@yahoo.com

\begin{abstract}
Purpose: This descriptive study was conducted to determine the relationship between nomophobia level and anxiety severity among university students.

Design and Methods: The study was completed with a total of 745 students. A descriptive questionnaire and the nomophobia questionnaire and measure of worry severity. Descriptive statistics, correlation analyses were used.

Finding: It was found positive correlation was determined between the nomophobia level and severity of anxiety.

Practical Implications: individuals with nomophobia should be given the necessary assistance before the current situation worsens. Information about the correct use of the smartphone should be provided.

\section{KEYWORDS}

mobile phone addiction, nomophobia, phobia, worry, young adults
\end{abstract}

\section{1 | INTRODUCTION}

Mobile phones and smart phones that have become a part of our lives make our lives easier but also cause negative situations, such as addiction or restlessness. ${ }^{1}$

Nomophobia, which is accepted as the phobia of the modern age, is the fear experienced by the individuals when they cannot reach the mobile device or communicate through mobile phone. In nomophobia, there are physical and mental conditions caused by unreasonable fear. ${ }^{2,3}$ Nomophobia is accepted as a modern aghophobia that enters into the lives of individuals as a product of the interaction between the mobile information and communication. ${ }^{2,4}$

Looking at the phone screen constantly to check the messages and incoming missed calls, misunderstanding the phone vibration or ringing tone, keeping the phone on for $24 \mathrm{~h}$, going to the bed with the phone, using the phone kept open all the time, and feeling anxiety and tense with the idea that the network is out of coverage are in nomophobia. ${ }^{5,6}$

Being out of the coverage area for mobile phone, using up its charge or forgetting to take the mobile phone with him/her cause anxiety that will negatively affect the individual's concentration in his/her daily life. They obsessively control the phones even if they have their phones with them. ${ }^{1,7}$ It has been observed that worry symptoms, such as difficulty in breathing, stomach cramps and dizziness negatively affect the daily life of the individual with nomophobia. The studies have conducted that nomophobia is gradually increasing and is one of the important psychological problems of our age. ${ }^{8}$ Sharma et al., ${ }^{9}$ concluded that $75 \%$ of medical students had nomophobia and experienced panic attacks when they cannot access their mobile phones.

It is seen that there is an increase in nomophobia with the widespread use of smartphones in these days. ${ }^{7}$ In the study conducted by Yildirim and Correra with university students in Turkey, they reported that $42.6 \%$ of young adults had nomophobia, their biggest fear was being unable to reach information and to communicate, and young adult women show more nomophobic behaviors than men. ${ }^{8}$ In a study conducted in England (2012), it was observed that while nomophobia rate was $70 \%$ in women, it was $61 \%$ in men and at most $77 \%$ of young adults in the age group of 18-24 were seen to have nomophobia. ${ }^{10}$ A study conducted among medical and engineering students in West Bengal in India showed that $42.6 \%$ of medical students and $44.6 \%$ of engineering students had nomophobia ${ }^{11}$

Since nomophobia, which arises as a result of increased use of smart phones, affects the young people, it negatively affects their academic lives and achievements. Nomophobia-prone students 
cannot concentrate on their lessons because their sleep patterns are disturbed. In a study conducted with 760 university students in France, it was seen that one-third of them experienced a fear of staying away from the smartphone and thus, their general health status, mental health and academic performance deteriorated. ${ }^{12}$

It is important to determine the degree of nomophobia, which is especially dependent on the use of smartphones, as it affects business, social life, academic relationships and other areas of life. ${ }^{13}$ Studies in the literature show the prevalence of nomophobia and the levels of nomophobic behavior of individuals, but there is no study examining the relationship between nomophobia and anxiety. Therefore, this study was conducted to examine whether nomophobia causes anxiety in young people. Therefore, we believe our research will fill this gap in the literature.

\section{1 | Research questions}

1. What are the nomophobia and anxiety severity levels of the young people?

2. What variables affect the nomofobia and anxiety severity levels of the young people

3. Is there any correlation between nomophobia and anxiety severity levels of young people?

\section{2 | METHODS}

\section{1 | Type of the study}

The study was conducted in descriptive type.

\subsection{The population and sample of the study}

The population of the study was composed of the students studying in the Departments of Nutrition ( $n=186$ ), physical therapy and rehabilitation (PTR) $(n=196)$ and nursing $(n=247)$, vocational school (VS), and Departments of Anesthesia ( $n=123)$, dialysis $(n=128)$, and paramedic ( $n=155$ ) of Hasan Kalyoncu University, Faculty of Health Sciences between January 4th and February 28th, 2020. No sampling method was determined and the sample of the study was composed of 745 students who met the inclusion criteria and attended the classes between the dates of the study. As a result of the power analysis, the sample size was determined with effect size of 0.25 , margin of error of $5 \%$, confidence interval of $95 \%$ and the power of representing the population of $90 \%$.

\section{3 | Data collection tools}

The data were collected by using personal information form, nomophobia questionnaire (NMP-Q), and measure of worry severity (MWS).

\subsection{1 | Personal information form}

It is a form including information about the students, such as age, gender, marital status, major, how many hours a day they spend on the mobile phone.

\subsection{2 | Nomophobia questionnaire (NMP-Q)}

It is a questionnaire developed by Yildirim and Correira ${ }^{10}$ to measure nomophobia levels of people. The questionnaire, which was adapted to Turkish by Yıldırım and Correira, ${ }^{10}$ is composed of 20 items. While the lowest score of the questionnaire is 20 points, its highest score is 140 points. Thus, $0-20$ points indicate no nomophobia, $21-60$ points indicate low nomophobia level, 61-100 points show moderate nomophobia level, and 101-140 points show high nomophobia level. ${ }^{14}$

\subsection{3 | Measure of worry severity (MWS)}

The scale, whose Turkish validity and reliability were conducted by Tunay and Soygüt, ${ }^{15}$ is composed of 8 items. While the lowest score of the scale is 0 , its highest score is 24 . High scores in the scale indicates high worry severity. The Cronbach's alpha value of the scale is $0.88 .{ }^{15}$ In this study, its Cronbach's alpha value was determined as 0.87 .

\subsection{Data collection}

The study was conducted between January 4th and February 28th, 2020. The questionnaire was applied to the students who agreed to participate in the study outside of class time. The researcher informed the students about the purpose of the study, the questionnaires were distributed and they were asked to fill them out under the supervision of the researcher. It took averagely $15 \mathrm{~min}$ to complete the questionnaire.

\subsection{Data assessment}

The data of the study were evaluated using SPSS 21.0 (Statistical Package of Social Sciences) packaged software. Number, percentage distributions, mean, standard deviation, $\chi^{2}, t$ test, one-way analysis of variance, and Pearson's correlation analysis were used to analyze the data. The value of $p<.05$ was accepted for statistical significance.

\subsection{Research variables}

\subsection{1 | Independent variables}

Features, such as age, gender, education department, marital status, daily phone and mobile internet usage times, number of daily checks on mobile phones, and seeing themselves as mobile addicts. 
TABLE 1 Comparison of NMP-Q and MWS mean scores of the participants in terms of their socio-demographic and mobile telephone usage characteristics $(n=745)$

\begin{tabular}{|c|c|c|c|c|c|c|}
\hline & \multirow[b]{2}{*}{$n$} & \multirow[b]{2}{*}{$\%$} & \multicolumn{2}{|l|}{ NMP-Q } & \multicolumn{2}{|l|}{ MWS } \\
\hline & & & $\underline{X} \pm S D$ & Significance & $\overline{X \pm S D}$ & Significance \\
\hline \multicolumn{7}{|l|}{ Gender $^{a}$} \\
\hline Female & 568 & 76.2 & $86.6 \pm 20.7$ & $t=4.202$ & $12.1 \pm 5.2$ & $t=3.967$ \\
\hline Male & 177 & 23.8 & $79.2 \pm 19.9$ & $p=0.000$ & $10.3 \pm 5.2$ & $p=0.000$ \\
\hline \multicolumn{7}{|l|}{ Age, years ${ }^{\mathrm{b}}$} \\
\hline $18-21$ & 583 & 78.3 & $86.3 \pm 20.9$ & $f=14.460$ & $12.1 \pm 5.2$ & $f=13.922$ \\
\hline $22-27$ & 150 & 20.1 & $81.5 \pm 18.3$ & $p=0.000$ & $10.4 \pm 5.1$ & $p=0.000$ \\
\hline 28 and over & 12 & 1.6 & $57.1 \pm 22.7$ & & $5.6 \pm 5.2$ & \\
\hline \multicolumn{7}{|l|}{ Department ${ }^{\mathrm{b}}$} \\
\hline Vocational school (VS) & 294 & 39.5 & $84.1 \pm 20.9$ & & $5.4 \pm 0.3$ & $f=1.542$ \\
\hline Nutrition & 155 & 20.8 & $83.6 \pm 20.0$ & $f=0.709$ & $5.1 \pm 0.4$ & $p=0.202$ \\
\hline Physical therapy (PTR) & 86 & 11.5 & $86.4 \pm 20.0$ & $p=0.547$ & $5.2 \pm 0.5$ & \\
\hline Nursing & 210 & 28.2 & $86.1 \pm 21.5$ & & $5.3 \pm 0.3$ & \\
\hline \multicolumn{7}{|l|}{ Marital status ${ }^{a}$} \\
\hline Married & 19 & 2.6 & $66.6 \pm 24.7$ & $t=-3.899$ & $7.6 \pm 5.8$ & $t=-3.374$ \\
\hline Single & 726 & 97.4 & $85.3 \pm 20.5$ & $p=0.000$ & $11.7 \pm 5.2$ & $p=0.001$ \\
\hline
\end{tabular}

How much time do you spend per day on the phone? $(h)^{b}$

$\begin{array}{lllllll}\text { Less than 1 } & 21 & 2.8 & 67.0 \pm 17.4 & & 8.0 \pm 4.7 & f=7.281 \\ \text { Between 1 and 3 } & 197 & 26.4 & 77.6 \pm 19.0 & f=21.094 & 10.8 \pm 5.1 & p=0.000 \\ \text { Between 3 and 5 } & 268 & 36.0 & 86.4 \pm 20.9 & p=0.000 & 11.7 \pm 5.3 & \\ \text { More than 5 } & 259 & 34.8 & 90.3 \pm 20.0 & & 12.5 \pm 5.3 & \end{array}$

How many times a day do you check the phone? ${ }^{\text {b }}$

$\begin{array}{lllllll}\text { Less than } 10 & 48 & 6.4 & 73.3 \pm 18.1 & & 10.5 \pm 5.7 & f=6.670 \\ 10-20 \text { times } & 197 & 26.4 & 77.9 \pm 20.0 & f=17.761 & 10.4 \pm 4.8 & p=0.000 \\ \text { 21-30 times } & 179 & 24.0 & 86.5 \pm 19.7 & p=0.000 & 11.9 \pm 5.3 & \\ 31-41 \text { times } & 118 & 15.8 & 85.7 \pm 19.3 & & 11.6 \pm 5.1 & \\ 41 \text { times and more } & 203 & 27.2 & 92.4 \pm 20.7 & & 12.9 \pm 5.4 & \end{array}$

How long is your daily mobile internet usage time? $(h)^{b}$

$\begin{array}{lllllll}\text { Less than 1 } & 161 & 21.6 & 77.8 \pm 19.3 & & 11.0 \pm 5.2 & f=8.897 \\ \text { Between 1 and 3 } & 244 & 32.8 & 81.4 \pm 18.9 & f=19.315 & 10.6 \pm 5.1 & p=0.000 \\ \text { Between 3 and 5 } & 184 & 24.7 & 88.9 \pm 21.6 & p=0.000 & 12.8 \pm 5.2 & \\ \text { More than 5 } & 156 & 20.9 & 92.7 \pm 20.6 & & 12.6 \pm 5.4 & \end{array}$

How long have you had a mobile phone? (years)

Less than 1

$15 \quad 2.0 \quad 79.2 \pm 22.4$

$13.3 \pm 5.5 \quad f=1.779$

Between 1 and 3

$60 \quad 8.1 \quad 74.8 \pm 18.6 \quad f=10.206$

$10.4 \pm 4.6 \quad p=0.150$

Between 3 and 5

$20527.5 \quad 81.6 \pm 20.0 \quad p=0.000$

$11.5 \pm 5.0$

More than 5

$\begin{array}{lll}465 & 62.4 & 87.8 \pm 20.7\end{array}$

$11.8 \pm 5.5$

Do you check your mobile phone as soon as you wake up in the morning? ${ }^{a}$

$\begin{array}{lllllll}\text { Yes } & 644 & 86.4 & 87.1 \pm 20.2 & t=7.602 & 11.9 \pm 5.3 & t=3.184 \\ \text { No } & 101 & 13.6 & 70.7 \pm 18.6 & p=0.000 & 10.1 \pm 5.2 & p=0.002\end{array}$

(Continues) 
TABLE 1 (Continued)

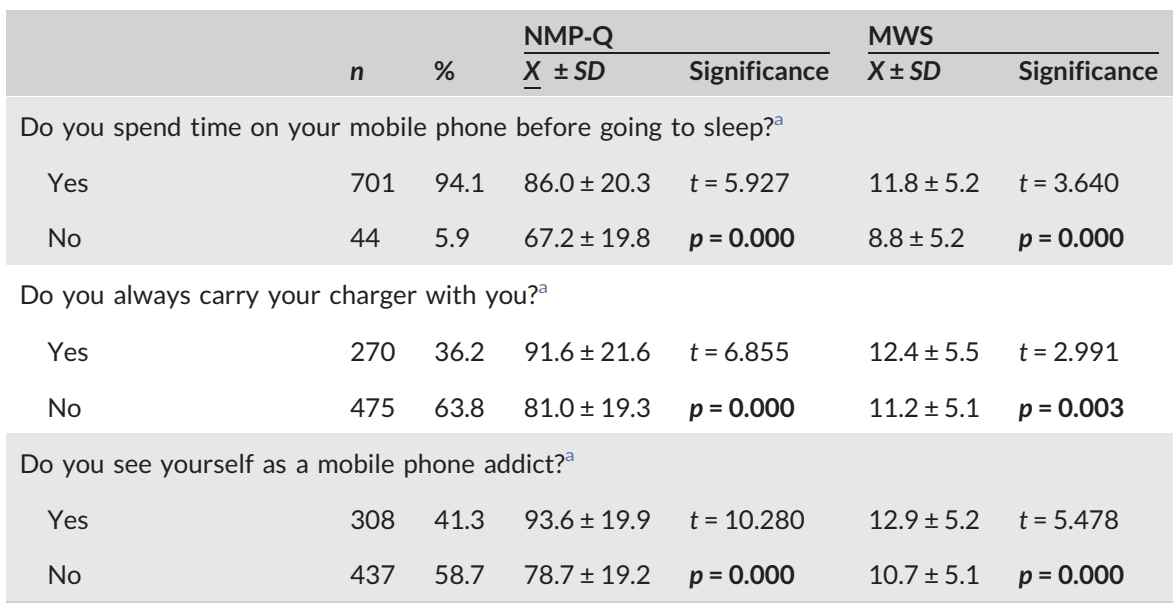

Note: Bold values are statistically significant at $p<0.05$.

Abbreviations: ANOVA, analysis of variance; NMP-Q, nomophobia questionnaire; MWS, measure of worry severity; PTR, physical therapy and rehabilitation; VS, vocational school.

andependent samples $t$ test.

${ }^{b}$ ANOVA.

\subsection{2 | Dependent variables}

Participants' scores from the nomophobia scale and anxiety severity scale

\subsection{Ethical considerations}

Before starting the study, approval was obtained from Hasan Kalyoncu University noninvasive ethics committee to conduct the study (Ethics Committee No:2019/96; Date: June 14th, 2019). After obtaining the ethics committee approval required for conducting the study, institutional permission was obtained from Rectorate of Hasan Kalyoncu University to conduct the study. Verbal and written consent was obtained from the participants by explaining the purpose of the study. The questionnaire did not contain any questions that could be used to identify students, and students' responses were kept confidential and anonymous. This study was conducted in accordance with the Declaration of Helsinki Principles.

\section{8 | Implications for nursing practice}

Today, nomophobia is an important problem that negatively affects the academic and social life of young people. Nomophobic ones should be determined from the students studying in my health sciences and it should be ensured that they receive the necessary help to solve the problem. Because the future nurses and healthcare workers being nomophobic will cause them to experience negative problems in their business relationships and social lives.

Nurses need to know about the factors that cause nomophobia, risky situations, and applications to be performed in the presence of nomophobia. School health nurses should provide training seminars and advise on nomophobia to prevent the spread of nomophobia in schools.

Nurses should identify individuals who are nomophobic, should take care of them one-to-one, inform the nomophobic individuals about what to do, and be in constant communication with these people. Nurses should act with individuals for the solution of the nomophobic problem and discuss their solutions. Nurses should constantly monitor nomophobic individuals, have information about their latest status, evaluate the situation together, and direct people who are at high risk for nomophobia to health institutions for help.

\section{3 | RESULTS}

In the present study conducted to investigate the relationship between the nomophobia level and worry severity of future healthcare professional candidates, it was determined that $78.3 \%$ of the participants were aged between 18 and 21 years, 76.2\% were female, and $97.4 \%$ were single. A total of $39.5 \%$ were VS students, $28.2 \%$ were nursing students, $20.8 \%$ were nutrition students, and $11.5 \%$ were PTR students (Table 1).

It was found that $36 \%$ of the participants stated that they spent $3-5 \mathrm{~h}$ a day on the mobile phone, $27.2 \%$ stated that they controlled their mobile phone more than 41 times a day, $32.8 \%$ spent $1-3 \mathrm{~h}$ a day by using mobile internet, and $62.4 \%$ stated that they had a mobile phone for more than 5 years. A total of $86.4 \%$ of the participants stated that they checked their mobile phone as soon as they woke up in the morning, $94.1 \%$ spent time with their mobile phone before going to sleep at night, $36.2 \%$ carried the charger with them all the time, and $41.3 \%$ saw themselves as mobile phone addict (Table 1).

A statistically significant difference was found between the gender, age, marital status, time spend daily on the phone, status of 
controlling phone daily, duration of daily mobile internet use, duration of having a mobile phone and NMP-Q mean scores of the participants $(p<0.05)$. A statistically significant difference was determined between the participants' status of checking telephone as soon as they wake up in the morning, status of spending time with phone before going to sleep, carrying the charger with them, status of seeing themselves as mobile phone addicts and NMP-Q mean scores $(p<0.05)$ (Table 1$)$.

A statistically significant difference was determined between the young people's gender, age, marital status, time they spent daily on phone, status of controlling telephone daily, daily mobile internet usage time and their MWS mean scores $(p<0.05)$. A statistically significant difference was determined between the participants' status of checking phone as soon as they wake up in the morning, their status of spending time on phone before going to sleep, status of carrying charger with them, status of seeing themselves as phone addicts and MWS mean scores $(p<0.05)$ (Table 1).

It was determined that the difference between the time spent by the participants on their mobile phones every day, the number of daily checks on their mobile phones, daily mobile internet usage times, mobile phone usage times and seeing themselves as mobile addicts was statistically significant $(p<0.05)$ (Table 2 ).

It was found that NMP-Q total mean score was $84.9 \pm 20.8$ and MWS total mean score was $11.6 \pm 5.3$ (Table 3).

A moderate positive correlation was determined between NMP$\mathrm{Q}$ total score and MWS total score $(r=0.431, p=0.000)$ (Table 4).

\section{4 | DISCUSSION}

Nomophobia, which is one of the most common new disorders in the world, is a behavioral addiction caused by the interaction between the individual and smartphones. ${ }^{10}$ Due to the anxiety and stress caused by nomophobia, the individuals limit their face-to-face social interaction and prefer to communicate with new technologies. The studies have shown that nomophobia has become widespread especially from young ages. ${ }^{8}$ For this reason, this study was conducted to determine the relationship between nomophobia and worry in young people.

In the present study, nomophobia levels of female students were determined to be higher than male students (Table 1 ). In the studies by Erdem et al., ${ }^{8}$ Okuyan et al., ${ }^{14}$ Gezginet al., ${ }^{16}$ Yıldırım et al., ${ }^{17}$ and Tavolacci et al., ${ }^{18}$ they determined that the nomophobia level of female students was higher compared to men. The results of this study are similar to the literature. There are studies in the literature stating that nomophobia does not differ by gender. It was determined that there was no difference between nomophobia and gender in the studies of Öz and Tortop ${ }^{19}$ and Burucuoğlu, ${ }^{3}$ while in the study by Pavithra and Madhukumar, ${ }^{20}$ nomophobia levels of men were found to be higher than women. High nomophobia level of women may be due to the fact that sociocultural characteristics, environmental factors, social learning and excessive use of the internet and mobile phone for socialization trigger nomophobia.
As the daily mobile phone usage time of the students participating in the present study increased, their nomophobia and worry levels were determined to increase (Table 1). In the studies by Erdem et al., ${ }^{8}$ Gezgin et al., ${ }^{16}$ and Okuyan et al., ${ }^{14}$ it was determined that the nomophobia levels increased as the daily phone usage time increased. The results we obtained were similar to the literature. It is believed that smart phone addiction is effective on nomophobia and worry severity. Today, telephone is used for many purposes and failure to reach these goals by the individuals causes certain levels of worry or discomfort. ${ }^{21}$ Smart phones reduce people's anxiety as it facilitates the ability to connect to the internet and social networks continuously. ${ }^{22}$

It was determined in this study that the students with high mobile internet usage time had higher nomophobia and worry severity levels (Table 1). In the studies by Gezgin et al., ${ }^{16}$ Gezgin and Çakır, ${ }^{23}$ and Gezgin et. al., ${ }^{24}$ it was determined that nomophobia level was high in individuals using mobile internet. The results we obtained are similar to the literature. The high amount of internet use in a day and problematic internet use can be thought to cause nomophobia. It was stated in the study by Rosales-Huamani et al., ${ }^{25}$ that students having nomophobia had problematic internet use.

Nomophobia tendencies were seen to increase as the year of using mobile phone increased (Table 1). It was found that while nomophobia tendencies of the students who had a long year of using phones increased in the studies by Nikhita et al., ${ }^{26}$ and Hoşgör et al., ${ }^{27}$ the time of having a smartphone had a positive correlation with nomophobia in the study by Yıldırım and Correia. ${ }^{10}$ The results of this study are similar to the literature. It can be thought that having a mobile phone for a long time triggered phone addiction, and phone addiction triggered nomophobia. Smart phones are important in human life, but cause severe addiction and nomophobia. ${ }^{27}$

Nomophobia levels of the students controlling their phones as soon as they wake up in the morning were found to be higher than those who did not (Table 1). This result is similar to the studies by Çelik and Atilla, ${ }^{12}$ Sırakaya, ${ }^{28}$ and Akıllı and Gezgin. ${ }^{7}$ It can be thought that mobile phone addiction increases the nomophobia level. In the study conducted by Aguilera-Manrique et al., ${ }^{29}$ on nomophobia, it was determined that there was a correlation between smartphone use and nomophobia.

In the present study, nomophobia and worry severity levels of the students carrying their chargers with them all the time were found to be higher than the students who did not (Table 1). In the studies by Çelik and Atilla, ${ }^{12}$ and Sırakaya, ${ }^{28}$ nomophobia levels of the students carrying their chargers were determined to be higher than the students who did not. The results of this study are similar to the literature. Personality traits, obsessions, and nomophobia, which will be triggered by being left without a phone after the battery runs out, may have an effect on the result. Running out of the battery of the smartphone is a concern in individuals with nomophobia. ${ }^{28,30}$

It was determined in the present study that the students had moderate nomophobia $(84.9 \pm 20.8)$ (Table 3$)$. In the studies by Aguilera-Manrique et al. ${ }^{29}(82.39 \pm 18.63)$, Al-Balhan et al. ${ }^{31}$ (82.71 \pm 22.68$)$, and Okuyanet al., ${ }^{14}(78.7 \pm 24.6)$, they determined 


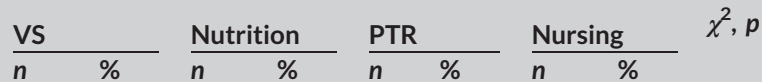

How much time do you spend per day on the phone? (h)

$\begin{array}{llllllllll}\text { Less than 1 } & 14 & 4.8 & 2 & 1.3 & 0 & 0 & 5 & 2.4 & \chi^{2}=21.842 \\ \text { Between 1 and 3 } & 90 & 30.6 & 38 & 24.5 & 26 & 30.2 & 43 & 20.5 & p=0.009 \\ \text { Between 3 and 5 } & 86 & 29.3 & 68 & 43.9 & 30 & 34.9 & 84 & 40.0 & \\ \text { More than 5 } & 104 & 35.4 & 47 & 30.3 & 30 & 34.9 & 78 & 37.1 & \end{array}$

How many times a day do you check your phone?

$\begin{array}{llllllllll}\text { Less than 10 } & 30 & 10.2 & 5 & 3.2 & 5 & 5.8 & 8 & 3.8 & \chi^{2}=40.210 \\ \text { 10-20 times } & 98 & 33.3 & 27 & 17.4 & 29 & 33.7 & 43 & 20.5 & p=0.000 \\ 21-30 \text { times } & 56 & 19.0 & 47 & 30.3 & 21 & 24.4 & 55 & 26.2 & \\ \text { 31-41 times } & 40 & 13.6 & 25 & 16.1 & 10 & 11.6 & 43 & 20.5 & \\ 41 \text { times and more } & 70 & 23.8 & 51 & 32.9 & 21 & 24.4 & 61 & 29.0 & \end{array}$

How long is your daily mobile internet usage time? (h)

$\begin{array}{llllllllll}\text { Less than 1 } & 99 & 33.7 & 8 & 5.2 & 32 & 37.2 & 22 & 10.5 & \chi^{2}=98.727 \\ \text { Between 1 and 3 } & 88 & 29.9 & 66 & 42.6 & 26 & 30.2 & 64 & 30.5 & p=0.000 \\ \text { Between 3 and 5 } & 58 & 19.7 & 53 & 34.2 & 19 & 22.1 & 54 & 25.7 & \\ \text { More than 5 } & 49 & 16.7 & 28 & 18.1 & 9 & 10.5 & 70 & 33.3 & \end{array}$

How long have you had a mobile phone? (years)

$\begin{array}{llllllllll}\text { Less than 1 } & 8 & 2.7 & 1 & 0.6 & 2 & 2.3 & 4 & 1.9 & \chi^{2}=18.362 \\ \text { Between 1 and 3 } & 23 & 7.8 & 13 & 8.4 & 6 & 7.0 & 18 & 8.6 & p=0.031 \\ \text { Between 3 and 5 } & 90 & 30.6 & 24 & 15.5 & 25 & 29.1 & 66 & 31.4 & \\ \text { More than 5 } & 173 & 58.8 & 117 & 75.5 & 53 & 61.6 & 122 & 58.1 & \end{array}$

Do you check your mobile phone as soon as you wake up in the morning?

$$
\begin{array}{llllllllll}
\text { Yes } & 253 & 86.1 & 137 & 88.4 & 71 & 82.6 & 183 & 87.1 & \chi^{2}=1.733 \\
\text { No } & 41 & 13.9 & 18 & 11.6 & 15 & 17.4 & 27 & 12.9 & p=0.630
\end{array}
$$

Do you spend time on your mobile phone before going to sleep?

$\begin{array}{llllllllll}\text { Yes } & 272 & 92.5 & 147 & 94.8 & 82 & 95.3 & 200 & 95.2 & \chi^{2}=2.209 \\ \text { No } & 22 & 7.5 & 8 & 5.2 & 4 & 4.7 & 10 & 4.8 & p=0.530\end{array}$

Do you always carry your charger with you?

$$
\begin{array}{llllllllll}
\text { Yes } & 108 & 36.7 & 63 & 40.6 & 27 & 31.4 & 72 & 34.3 & \chi^{2}=2.553 \\
\text { No } & 186 & 63.3 & 92 & 59.4 & 59 & 68.6 & 138 & 65.7 & p=0.466
\end{array}
$$

Do you see yourself as a mobile phone addict?

$$
\begin{array}{llllllllll}
\text { Yes } & 102 & 34.7 & 74 & 47.7 & 38 & 44.2 & 94 & 44.8 & \chi^{2}=9.276 \\
\text { No } & 192 & 65.3 & 81 & 52.3 & 48 & 55.8 & 116 & 55.2 & \boldsymbol{p}=0.026
\end{array}
$$

Note: Bold values are statistically significant at $\mathrm{p}<0.05$ (chi-square test).

Abbreviations: PTR, physical therapy and rehabilitation; VS, vocational school.

that students had moderate nomophobia. The findings of this study are similar to the literature. However, when examining the mean scores, the present study is at the same level with the other studies, however, nomophobia total mean score is seen to be higher. It can be thought that young people's perceptions of life, personality traits,
TABLE 2 Distribution of the students' characteristics regarding the use of mobile phones according to their departments 
TABLE 3 NMP-Q and MWS total and subscale scores of the students $(n=745)$

\begin{tabular}{lll}
\hline & Min-max & $X \pm S D$ \\
\hline $\begin{array}{l}\text { NMP-Q unable to access information } \\
\text { subscale }\end{array}$ & $4-28$ & $17.8 \pm 5.0$ \\
\hline NMP-Q giving up convenience subscale & $5-35$ & $20.7 \pm 6.5$ \\
\hline NMP-Q unable to communicate subscale & $6-42$ & $27.0 \pm 7.2$ \\
\hline NMP-Q losing connection subscale & $5-35$ & $19.2 \pm 6.3$ \\
\hline NMP-Q total & $25-140$ & $84.9 \pm 20.8$ \\
\hline MWS total & $0-24$ & $11.6 \pm 5.3$ \\
\hline
\end{tabular}

Abbreviations: MWS, measure of worry severity; NMP-Q, nomophobia questionnaire.

The fact that the students had medium worry levels may be caused by their moderate nomophobia levels. In addition, telephone addiction, obsessive behavior, and personality traits can also have an effect on the result. In the studies determining the relationship between the personal traits and smart phone addiction or nomophobia, it is suggested that personal traits and disorders can have a catalyst effect in nomophobia. ${ }^{8}$ Behaviors, such as continuously checking if there are calls or messages, having concern and stress in the places which are outside of coverage or have restricted use are observed in people with nomophobia. ${ }^{32,33}$

A positive correlation was determined between NMP-Q total score and MWS total score $(r=0.431, p=0.000$ ) (Table 4). The fact that the worry level increased as the nomophobia severity level

TABLE 4 Correlation of NMP-Q and MWS total and subscale scores

\begin{tabular}{|c|c|c|c|c|c|c|}
\hline & & 1 & 2 & 3 & 4 & 5 \\
\hline $\begin{array}{l}\text { NMP-Q unable to } \\
\text { access } \\
\text { information } \\
\text { subscale (1) }\end{array}$ & & & & & & \\
\hline $\begin{array}{l}\text { NMP-Q giving up } \\
\text { convenience } \\
\text { subscale (2) }\end{array}$ & $\begin{array}{l}r \\
p\end{array}$ & $\begin{array}{l}0.589^{*} \\
0.000\end{array}$ & & & & \\
\hline $\begin{array}{l}\text { NMP-Q unable to } \\
\text { communicate } \\
\text { subscale (3) }\end{array}$ & $r$ & $\begin{array}{l}0.499^{*} \\
0.000\end{array}$ & $\begin{array}{l}0.600^{*} \\
0.000\end{array}$ & & & \\
\hline $\begin{array}{l}\text { NMP-Q losing } \\
\text { connection } \\
\text { subscale (4) }\end{array}$ & $\begin{array}{l}r \\
p\end{array}$ & $\begin{array}{l}0.495^{*} \\
0.000\end{array}$ & $\begin{array}{l}0.631^{*} \\
0.000\end{array}$ & $\begin{array}{l}0.584^{*} \\
0.000\end{array}$ & & \\
\hline NMP-Q total (5) & $\begin{array}{l}r \\
p\end{array}$ & $\begin{array}{l}0.755^{*} \\
0.000\end{array}$ & $\begin{array}{l}0.861^{*} \\
0.000\end{array}$ & $\begin{array}{l}0.837^{*} \\
0.000\end{array}$ & $\begin{array}{l}0.829^{*} \\
0.000\end{array}$ & \\
\hline MWS total (6) & $r$ & $\begin{array}{l}0.348^{*} \\
0.000\end{array}$ & $\begin{array}{l}0.419^{*} \\
0.000\end{array}$ & $\begin{array}{l}0.333^{*} \\
0.000\end{array}$ & $\begin{array}{l}0.321^{*} \\
0.000\end{array}$ & $\begin{array}{l}0.431^{*} \\
0.000\end{array}$ \\
\hline
\end{tabular}

Abbreviations: MWS, measure of worry severity; NMP-Q, nomophobia questionnaire.

$p<0.01$ (*corelation test). increased may be caused by that nomophobia causes or triggers worry. It can also be thought that personality traits and stress and anxiety caused by mobile phone addiction may trigger worry and in turn worry may trigger nomophobia. Frequent (perhaps compulsive) use of mobile phones is positively associated with mobile phone addiction, anxiety, depression, and stress. Individuals with obsessive behaviors (such as checking their pockets every ten seconds to see what is happening) are more concerned about "inability to communicate with others" and/or "giving up convenience." ${ }^{\text {"34 }}$

\section{1 | Limitations}

This study is limited by the sample and time frame in which the study was conducted. Research findings are limited to the data obtained from the answers given to the questionnaire and scale forms used (personal information form, nomophobia scale, and anxiety severity scale).

\section{5 | CONCLUSION}

As a result of this study, it was found that nomophobia levels of the students were moderate and there was a positive correlation between nomophobia level and worry level. Female students had higher level of nomophobia than male students and as daily internet and phone use durations increased, their nomophobia and worry levels increased. The years of mobile phone use increased, their nomophobia tendencies increased and the students carrying their chargers with them all the time and controlling their cell phone as soon as they wake up in the morning had higher levels of nomophobia.

In accordance with the results obtained at the end of the study, it is recommended to conduct more comprehensive studies determining how nomophobia, the new phenomenon of modern age, affects daily, academic, and business lives of individuals and to make necessary interventions based on the obtained results. Necessary help should be given to individuals or students, who are thought to have nomophobia, before current condition aggravates or reaches to an irrevocable level. It is recommended to provide information about correct use of smart phone and develop strategies in this matter.

\section{ACKNOWLEDGMENT}

The authors would like to thank to all individuals who participated in the research.

\section{CONFLICT OF INTERESTS}

The authors declare that there are no conflict of interests

\section{AUTHOR CONTRIBUTIONS}

Study design: Filiz Polat. Data collection and/or analysis: Leyla Delibaş and ibrahim Bilir. Preparation of the article: Filiz Polat, Leyla Delibaş, and ibrahim Bilir. 


\section{DATA AVAILABILITY STATEMENT}

The data that support the findings of this study are available from the corresponding author upon reasonable request.

\section{ORCID}

Filiz Polat (D) https://orcid.org/0000-0001-8326-9504

Leyla Delibaş (ID) https://orcid.org/0000-0002-9529-5459

Ibrahim Bilir (D) https://orcid.org/0000-0002-0110-3867

\section{REFERENCES}

1. Adnan M, Gezgin DM. A modern phobia: prevalence of nomophobia among college students. Ankara Univ J Faculty Educ Sci. 2016;49(1): 141-158.

2. Olivencia-Carrióna MA, Ferri-Garcíab R, Ruedab Del Mar M, Jiménez-Torresa GM, López-Torrecillasa F. Temperament and characteristics related to nomophobia. Psychiatry Res. 2018;266: 5-10. https://doi.org/10.1016/j.psychres.2018.04.056

3. Burucuoğlu M. A research on nomophobia levels of vocational college students. J Karabuk Univ Institute Soc Sci. 2017;2:482-489.

4. Kocabaş D, Korucu SK. The disease of digital era: nomophobia. Eurasian J Res Soc Econ. 2018;5(11):254-268.

5. Adawi M, Bragazzi NL, Argumosa-Villar L, et al. Translation and validation of the nomophobia questionnaire in the Italian language: exploratory factor analysis. JMIR Mhealth Uhealth. 2018;6(1):1-12 https://doi.org/10.2196/mhealth.9186

6. Erdem H, Kalkın G, Türen U, Deniz M. The effects of no mobıle phone phobia (nomofobi) on academic performance among undergraduate students. Suleyman Demirel Univ J Faculty Econ Administrative Sci. 2016; 21(3):923-936.

7. Akıllı KG, Gezgin MD. Examination of relationship between university students' nomophobia levels and behavior patterns. Mehmet Akif Ersoy Univ J Educ Faculty. 2016;40:51-69.

8. Erdem H, Türen U, Kalkın G. No mobile phone phobia (nomophobia) prevalence: samples of undergraduate students and public employees from Turkey. Inf Technol J. 2017;10(1):1-12.

9. Sharma N, Sharma P, Sharma N, Wavare RR. Rising concern of nomophobia amongst Indian medical students. J Res Med Sci. 2015;3: 705-707. https://doi.org/10.5455/2320-6012.ijrms20150333

10. Yıldırım Ç, Correia A. Exploring the dimensions of nomophobia: development and validation of a self-reported questionnaire. Comput Human Behav. 2015;49:130-137. https://doi.org/10.1016/j. chb.2015.02.059

11. Dasgupta P, Bhattacherjee S, Dasgupta S, Roy JK, Mukherjee A, Biswas R. Nomophobic behaviors among smartphone using medical and engineering students in two colleges of West Bengal. Indian J Public Health. 2017;61:199-204. https://doi.org/10.4103/ijph.IJPH_81_16

12. Çelik $\mathrm{Y}$, Atilla $\mathrm{G}$. Investigation of the relationship between the nomofobia, difficulties in emotion regulation and academic achievements of the university students: a study on Manavgat Vocational School. Intl J Acad Value Studies. 2018;5(26):2628-2639.

13. São-Romão-Preto L, Granados-Gámez G, Gutiérrez-Puertas V, Aguilera-Manrique G. Comparative study of nomophobia among Spanish and Portuguese nursing students. Nurse Educ Pract. 2019; 34:79-84. https://doi.org/10.1016/j.nepr.2018.11.010

14. Okuyan CB, Güner PD, Güneş SU. Determination of nomophobia levels of nursing and medical students. Gümüşhane Univ J Health Sci. 2019;8(4):372-382.

15. Tunay Ş, Soygüt G. Reliability and validity of anxiety severity scale on Turkish university students. Turk J Psychiatry. 2009;20(1):68-74.

16. Gezgin DM, Şumuer E, Arslan O, Yıldırım S. Nomophobia prevalence among pre-service teachers: a case of Trakya University. J Trakya Univ Faculty Educ. 2017;7(1):86-95.
17. Yıldırım C, Sumuer E, Adnan M, Yıldırım SA. Growing fear: prevalence of nomophobia among Turkish college students. Inf Dev. 2016;32(5):1322-1331.

18. Tavolacci MP, Meyrignac G, Richard L, Dechelotte P, Ladner J. Problematic use of mobile phone and nomophobia among French college students. Eur J Public Health. 2015;25(suppl 3):206. https:// doi.org/10.1093/eurpub/ckv172.088

19. Öz H, Tortop HS. Investigation of university students' nomophobia levels between personality types. E-J New Media, 2(3), 146-159. https://doi.org/10.17932/IAU.EJNM.25480200.2018. 2/3.146-159

20. Pavithra M, Madhukumar S, Mahadeva M. A study on nomophobiamobile phone dependence, among students of a medical college in Bangalore. Nat J Community Med, 2015;6(3):340-344.

21. Eren B, Kılıç ZN, Günal SE, Kırcalı MF, Öznacar BB, Topuzoğlu A. Evaluation of nomophobia and related factors in high school students. Anatolian J Psychiatry. 2020;21(2):133-140. https://doi.org/ 10.5455/apd.56124

22. Güler EÖ, Veysikarani D. A research on nomophobia: example of university students. Beykoz Acad J. 2019;7(1):75-88. https://doi.org/ 10.14514/BYK.m.26515393.2019.7/1.75-88

23. Gezgin DM, Çakır Ö. Analysis of nomophobic behaviors of adolescents regarding various factors. J Human Sci. 2016;13(2):2504-2519. https://doi.org/10.14687/jhs.v13i2.3797

24. Gezgin DM, Çakır Ö, Yıldırım S. The relationship between levels of nomophobia prevalence and internet addiction among high school students: the factors influencing nomophobia. Intl J Res Educ Sci. 2018;4(1):215-225. https://doi.org/10,21890/ijres. 383153

25. Rosales-Huamani JA, Guzman-Lopez RR, Aroni-Vilca EE, Matos Avalos CR, Castillo-Sequera JL. Determining symptomatic factors of nomophobia in peruvian students from the national university of engineering. Appl Sci. 2019;9:1814.

26. Nikhita CS, Jadhav PR, Ajinkya SA. Prevalence of mobile phone dependence in secondary school adolescents. J Clin Diagn Res. 2015;9(11):6-9. https://doi.org/10.7860/JCDR/2015/14396.68 03

27. Hoşgör H, Tandoğan Ö, Hoşgör DG. Effect of nomophobia on duration of daily smartphone usage and school success: the example of health personnel candidates. J Acad Soc Sci. 2017;5(46):573-595. https://doi.org/10.16992/ASOS.12266

28. Sırakaya M. Examination of associate students' nomophobia levels according to smart phone use. Mersin Univ J Faculty Educ. 2018;14(2):714-728. https://doi.org/10.17860/mersinefd.359 458

29. Aguilera-Manrique G, Ma'rquezHerna'ndez VV, Alcaraz-Co'rdoba T, Granados GG, Gutie'rrez-Puertas V, Gutie'rrez-Puertas L. The relationship between nomophobia and the distraction associated with smartphone use among nursing students in their clinical practicum. PLOS One. 2018;13(8):1-14. https://doi.org/10.1371/journal.pone. 0202953

30. Gezgin DM, Şahin YL, Yıldırım S. The investigation of social network users' nomophobia levels regarding to various factors. Educ Technol Theory Pract. 2017;7(1):1-15.

31. Al-Balhan EM, Khabbache H, Watfa A, Re TS, Zerbetto $R$ Bragazzi NL. Psychometric evaluation of the Arabic version of the nomophobia questionnaire: confirmatory and exploratory factor analysis-implications from a pilot study in Kuwait among university students. Psychol Res Behav Manag. 2018;11:417-482. https://doi. org/10.2147/PRBM.S169918

32. Işı M, Kaptangil i. The relation of smart phone addiction to social media usage and five factor personality trait: a research on university students. J Human Soc Sci Res. 2018;7(2):695-717. https:// doi.org/10.15869/itobiad.361081 
33. Minaz A, Bozkurt ÖÇ. Investigation of university students smartphone addiction levels and usage purposes in terms of different variables. Mehmet Akif Ersoy Univ J Soc Sci Institute. 2017;9(21): 268-286. https://doi.org/10.20875/makusobed.306903

34. Lee S, Kim M, Mendoza JS, McDonough IM. Addicted to cellphones: exploring the psychometric properties between the nomophobia questionnaire and obsessiveness in college students. Heliyon. 2018 ; 4(11):1-20. https://doi.org/10.1016/j.heliyon.2018.e00895
How to cite this article: Polat F, Delibaş L, Bilir i. The relationship between nomophobia level and worry severity in future healthcare professional candidates. Perspect Psychiatr Care. 2021;1-9.

https://doi.org/10.1111/ppc.12792 